\title{
Sự phát triển của ngành thương mại điện tử trong thời kì Covid-19
}

\author{
Hoàng Phương Linh, Nguyễn Thuỳ Linh, Trương Khánh Linh \\ Phùng Thị Nhật Linh, Nguyễn Khánh Linh
}

Đại học Quốc gia

Ngày 12 Tháng Hai 2022

Preprint DOI: https://osf.io/tn52s

\begin{abstract}
Ở Việt Nam và thế giới đang phải đối mặt với sự bùng nổ của dịch bệnh Covid-19. Dịch bệnh một mặt đã có tác động sâu xắc đến toàn bộ nền kinh tế và đời sống của người dân, nhưng mặt khác cũng thúc đẩy chuyển mình của nhiều ngành để thích ứng với sự kéo dài của đại dịch (La, 2020). Một trong những ngành bùng nổ trong đại dịch, được coi là điểm sáng của nền kinh tế nước nhà nói riêng và quốc tế nói chung chính là ngành thương mại điện tử (TMĐT). Trước đây, khi đại dịch chưa xảy ra, ngành thương mại điện tử đã được đánh giá là một ngành tiềm năng lớn nhưng vẫn chưa đủ cạnh tranh với việc mua sắm truyền thống (trực tiếp). Tuy vậy, cục diện đã thay đổi hoàn toàn khi toàn thế giới đối mặt với Covid-19, ngành thương mại điện tử đã lợi dụng những điểm hạn chế của đại dịch để biến thành điểm mạnh của ngành. Nhận thấy sự thay đổi và phát triển vượt bậc của ngành thương mại điện tử và sự biến đổi to lớn của nó trong đại dịch Covid-19, chúng em nhận thấy đây là một đề tài rất hấp dẫn và thiết thực. Dưới kiến thức từ bộ môn, sự chỉ dạy của giảng viên và cảm hứng từ những tiết học, nhóm 9 chúng em đã chọn đề tài là:
\end{abstract}

"Sự phát triển của ngành thurong mại điện tử trong thời kì Covid-19".

Tiểu luận gồm hai phần lớn. Trong đó Phần 1 trình bày về đề tài được chọn: Giới thiệu chung về thương mại điện tử và đề cập đến thực tế của vấn đề trước dịch bệnh. Phần 2 đưa ra sự quan sát chung về tình hình thương mại điện tử trong dịch bệnh và thực tế sự phát triển của các sàn thương mại điện tử tại Việt Nam nhằm thảo luận để phân tích, đánh giá và có góc nhìn rộng hơn đối với sự phát triển của thương mại điện tử.

Sau đây chúng em xin trình bày Phần 1 . 


\section{A. GIỚI THIÊU CHUNG}

\section{Lịch sử của ngành thương mại điện tử}

Về nguồn gốc, thương mại điện tử được xem như là điều kiện thuận lợi của các giao dịch thương mại điện tử, sử dụng công nghệ như EDI và EFT. Cả hai công nghệ này đều được giới thiệu thập niên 70, cho phép các doanh nghiệp gửi các hợp đồng điện tử như đơn đặt hàng hay hóa đơn điện tử. Sự phát triển và chấp nhận của thẻ tín dụng, máy rút tiền tự động (ATM) và ngân hàng điện thoại vào thập niên 80 cũng đã hình thành nên thương mại điện tử. Một dạng thương mại điện tử khác là hệ thống đặt vé máy bay bởi Sabre ở Mỹ và Travicom ở Anh.

Vào thập niên 90, thương mại điện tử bao gồm các hệ thống hoạch định tài nguyên doanh nghiệp (ERP), khai thác dữ liệu và kho dữ liệu.

Năm 1990, Tim Berners-Lee phát minh ra WorldWideWeb trình duyệt web và chuyển mạng thông tin liên lạc giáo dục thành mạng toàn cầu được gọi là Internet (www). Các công ty thương mại trên Internet bị cấm bởi NSF cho đến năm 1995. Mặc dù Internet trở nên phổ biến khắp thế giới vào khoảng năm 1994 với sự đề nghị của trình duyệt web Mosaic, nhưng phải mất tới 5 năm để giới thiệu các giao thức bảo mật (mã hóa SSL trên trình duyệt Netscape vào cuối năm 1994) và DSL cho phép kết nối Internet liên tục. Vào cuối năm 2000, nhiều công ty kinh doanh ở Mỹ và Châu Âu đã thiết lập các dịch vụ thông qua World Wide Web. Từ đó con người bắt đầu có mối liên hệ với từ "ecommerce" với quyền trao đổi các loại hàng hóa khác nhau thông qua Internet dùng các giao thức bảo mật và dịch vụ thanh toán điện tử.(Ban biên tập Cục Tin Học Hóa, 2014) 



\section{Thương mại điện tử là gì?}

Thương mại điện tử hay còn gọi là e-commerce, e-comm hay $\mathrm{EC}$, là sự mua bán sản phẩm hay dịch vụ trên các hệ thống điện tử như Internet và các mạng máy tính.

- Theo Tổ chức Thương mại thế giới (WTO): "TMĐT bao gồm việc sản xuất, quảng cáo, bán hàng và phân phối sản phẩm được mua bán và thanh toán trên mạng Internet, nhưng được giao nhận một cách hữu hình, cả các sản phẩm giao nhận cũng như những thông tin số hoá thông qua mạng Internet".

- Theo Hiệp hội các quốc gia Đông Nam Á (ASEAN): "TMĐT là các giao dịch điện tử trên mạng Internet hoặc những mạng mở khác. Những giao dịch này có hai loại: Một là giao dịch bán dịch vụ và hàng hóa hữu hình. Hai là, giao dịch liên quan đến việc chuyển trực tiếp, trực tuyến các thông tin và dịch vụ, hàng hóa số hóa".

Tại Việt Nam, ngày 16/5/2013, Chính phủ ban hành Nghị định số 52/2013/NĐCP về TMĐT: "Hoạt Động TMĐT là việc tiến hành một phần hoặc toàn bộ quy trình của hoạt động thương mại bằng phương tiện điện tử có kết nối với mạng Internet, mạng viễn thông di động hoặc các mạng mở khác”. (Nguyễn Ngọc Hưng, 2017)

\section{Chủ thể của ngành thương mại điện tử}

Chủ thể của hoạt động trong TMĐT được chia thành năm nhóm chính, đó chính là:

- Nhóm người sử hữu website TMĐT để bán hàng;

- $\quad$ Nhóm cung cấp dịch vụ TMĐT;

- Nhóm người bán;

- Nhóm là khách hàng và nhóm cung cấp hạ tầng.

Bên cạnh đó, còn có thể có sự tham gia của các chủ thể là cơ quan, tổ chức chứng thức, hoặc giám sát đảm bảo đảm an toàn trong TMĐT. Các thương nhân, tổ chức, cá nhân Việt Nam; cá nhân nước ngoài cư trú tại Việt Nam; hoặc thương nhân, tổ chức nước ngoài có sự hiện diện tại Việt Nam thông qua hoạt động đầu tư; lập chi nhánh, văn phòng đại diện; hoặc thiết lập website dưới tên miền Việt Nam 
là những chủ thể tham gia vào TMĐT, đóng các vai trò khác nhau của hoạt động nêu trên. (Ban biên tập Luật sư X, 2021)

\section{Các mô hình thương mại điện tử}

Theo tốc độ phát triển mạnh mẽ của internet, thị trường thương mại điện tử đã và đang phủ sóng ngày càng mạnh mẽ. Không chỉ trong nước mà trên thế giới, các mô hình thương mại điện tử cũng dần được phát triển và chứng tỏ được tầm quan trọng của mình. Hiện tại, thương mại điện tử được chia ra tổng cộng 9 loại mô hình với đầy đủ các đặc điểm và tính chất riêng.

\section{Doanh nghiệp với Doanh nghiệp (B2B)}

Thương mại điện tử giữa doanh nghiệp với doanh nghiệp đề cập đến việc trao đổi điện tử các sản phẩm, dịch vụ hoặc thông tin giữa các doanh nghiệp. Đây là mô hình TMĐT gắn với mối quan hệ giữa các công ty với nhau. Ví dụ bao gồm các thư mục trực tuyến và các trang web trao đổi sản phẩm và cung cấp cho phép doanh nghiệp tìm kiếm sản phẩm, dịch vụ và thông tin và bắt đầu giao dịch thông qua giao diện mua sắm điện tử.

\section{Doanh nghiệp với Nguời tiêu dùng $(B 2 C)$}

TMĐT giữa doanh nghiệp với người tiêu dùng là bộ phận bán lẻ của TMĐT trên internet. Đó là khi doanh nghiệp bán sản phẩm, dịch vụ hoặc thông tin trực tiếp cho người tiêu dùng. Ngày nay, có vô số cửa hàng và trung tâm ảo trên internet bán tất cả các loại hàng tiêu dùng. Ví dụ được công nhận nhất của các trang web này là Amazon, công ty thống trị thị trường B2C.

\section{Nguời tiêu dùng với Người tiêu dùng (C2C)}

Đây là một mô hình TMĐT trong đó người tiêu dùng trao đổi sản phẩm, dịch vụ và thông tin với nhau trực tuyến. Các giao dịch này thường được thực hiện thông qua một bên thứ ba cung cấp một nền tảng trực tuyến mà các giao dịch được thực hiện.

\section{Nguời tiêu dùng với Doanh nghiệp (C2B)}


C2B là một loại mô hình TMĐT trong đó người tiêu dùng làm cho sản phẩm và dịch vụ của họ có sẵn trực tuyến để các công ty đấu thầu và mua. Điều này trái ngược với mô hình thương mại truyền thống của B2C. (Ban biên tập Luật sư X, 2021)

\section{Các phương tiện của thương mại điện tử}

\section{1. Điện thoại}

Điện thoại là một phương tiện phổ thông, dễ sử dụng, và gần như xuất hiện sớm nhất trong các phương tiện điện tử được đề cập. Một số dịch vụ có thể cung cấp trực tiếp qua điện thoại như dịch vụ bưu điện, ngân hàng, hỏi đáp, tư vấn, giải trí. Với sự phát triển của điện thoại di động, liên lạc qua vệ tinh, ứng dụng của điện thoại đang và sẽ trở nên rộng rãi hơn. Nhưng điện thoại có một hạn chế là chỉ truyền tải được âm thanh và mọi cuộc giao dịch vẫn phải kết thúc bằng giấy tờ. Ngoài ra, chi phí giao dịch bằng điện thoại, nhất là giao dịch điện thoại đường dài, còn khá đắt. Thương mại điện tử vẫn sử dụng điện thoại như một công cụ quan trọng, tuy nhiên "điện thoại" được hiểu theo nghĩa rộng, không giới hạn ở điện thoại cố định mà được hiểu là tất cả các hình thức giao tiếp bằng giọng nói thông qua các phương tiện điện tử: điện thoại qua Internet, "voice chat", "voice message" qua Yahoo Messenger (YM) hay Skype... Đây cũng chính là lợi thế nổi bật của Internet với các ứng dụng truyền thoại qua môi trường này và các thiết bị điện tử như máy tính được sử dụng trong giao dịch thương mại điện tử này. Ví dụ: đàm phán, ký kết hợp đồng qua YM \& thư điện tử.

\section{Máy fax}

Có thể thay thế dịch vụ đưa thư và gửi công văn truyền thống. Tuy nhiên hạn chế của máy fax là chỉ truyền được văn bản viết, không truyền tải được âm thanh, hình ảnh động, hình ảnh ba chiều. Fax qua Internet là một dịch vụ mới được ứng dụng khá rộng rãi để giảm chi phí trong giao dịch điện tử. Thiết bị điện tử cũng không giới hạn ở máy fax truyền thống mà mở rộng ra máy vi tính và các thiết bị điện tử khác sử dụng các phần mềm cho phép gửi và nhận văn bản fax. Hoạt động này cũng làm mở rộng khái niệm thương mại điện tử và những quy định về văn bản gốc, bằng chứng, văn bản do bản gốc của fax trước đây là văn bản giấy, bản gốc của fax qua máy vi tính có thể là văn bản điện tử. Ví dụ: sử dụng winfax gửi văn bản word từ máy vi tính đến máy fax của đối tác. 


\section{Truyè̀n hình}

Ngày nay, truyền hình trở thành một trong những công cụ điện tử phổ thông nhất. Truyền hình đóng vai trò quan trọng trong thương mại, nhất là trong quảng cáo hàng hóa. Song truyền hình mới chỉ là một công cụ truyền thông một chiều, qua truyền hình, khách hàng không thể tìm kiếm được các chào hàng, không thể đàm phán với người bán về các điều khoản mua bán cụ thể. Gần đây, khi máy thu hình được kết nối với máy tính thì công dụng của nó được mở rộng hơn. Việc giao dịch và đàm phán bằng "video conference" thực hiện qua Internet trở nên quan trọng và đẩy mạnh thương mại điện tử khi tiết kiệm được thời gian và chi phí của các bên mà vẫn có hiệu quả như đàm phán giao dịch trực tiếp truyền thống. Ví dụ: e-learning sử dụng videoconference và net-meeting.

\section{Máy tính và mạng Internet}

Thương mại điện tử chỉ thực sự có vị trí quan trọng khi có sự bùng nổ của máy tính và internet vào những năm 90 của thế kỷ 20 . Máy tính và Internet giúp doanh nghiệp tiến hành giao dịch mua bán, hợp tác trong sản xuất, cung cấp dịch vụ, quản lý các hoạt động trong nội bộ doanh nghiệp, liên các các doanh nghiệp trên toàn cầu, hình thành các mô hình kinh doanh mới. Không chỉ giới hạn ở máy tính, các thiết bị điện tử và các mạng viễn thông khác cũng được ứng dụng mạnh mẽ vào thương mại làm đa dạng các hoạt động thương mại điện tử từ việc sử dụng thẻ thông minh trong thanh toán điện tử, mobile phone trong các giao dịch điện tử giá trị nhỏ, hệ thống thương mại điện tử trong giao thông để xử lý vé tàu điện, xe bus, máy bay đến giao dịch chứng khoán, tài chính, ngân hàng điện tử, hai quan điện tử trong nước và quốc tế. Những tập đoàn toàn cầu cũng chia sẻ thông tin trong hoạt động thương mại qua mạng riêng của mình hoặc qua internet. Ví dụ: ngân hàng điện tử (e-banking), mua sắm điện tử (e-procurement). (Ban biên tập Quản lý doanh nghiệp, 2020)

\section{B. THƯƠNG MẠI ĐIỆN TỬ TRƯớC DỊCH BỆNH}

\section{Quá trình phát triển của thương mại điện tử trước dịch Covid-19}

Trong 11 năm từ 2006 - 2017, Quảng cáo trực tuyến tăng lên con số khoảng 200 lần từ 3 triệu đô (2006) lên đến 600 triệu đô (2017). Đây là con số khá ấn 
tượng, cho thấy sự phát triển của quảng cáo trực tuyến khá tương đồng với sự phát triển của Thương mại Điện tử.

Năm 2017, Thương mại điện tử Việt Nam đánh dấu sự bùng nổ về thương mại điện tử xuyên biên giới. Tốc độ tăng trưởng của thị trường TMĐT trong năm 2017, 2018 ước tính trên $25 \%$. Riêng với lĩnh vực bán lẻ trực tuyến, thông tin từ hàng nghìn website TMĐT cho thấy tỷ lệ tăng trưởng doanh thu năm 2017 tăng $35 \%$. Với lĩnh vực thanh toán, năm 2017, tăng trưởng số lượng giao dịch trực tuyến thẻ nội địa tăng khoảng $50 \%$ so với năm 2016 trong khi giá trị giao dịch tăng trưởng tới $75 \%$.

\section{Nhũng đặc điểm nổi bật của thương mại điện tử trước dịch Covid-19}

Theo kết quả điều tra khảo sát năm 2016, có $6 \%$ người mua hàng trực tuyến trả lời rất hài lòng với phương thức mua hàng này; $41 \%$ người mua trả lời hài lòng, tăng đáng kể so với tỷ lệ $29 \%$ của năm $2015 ; 48 \%$ người mua cho biết cảm thấy bình thường và chỉ $5 \%$ số người được hỏi trả lời không hài lòng. Giá trị sản phẩm dịch vụ người mua hàng chọn mua nhiều nhất là mức từ 1 đến 3 triệu đồng, chiếm $29 \%$. Theo sau là mức trên 5 triệu đồng với $26 \%$ người chọn mua và mức được ít người chọn mua nhất là từ 3 đến 5 triệu đồng với 11\%.(Trần Thị Kim Phượng, 2018)

Trong những năm gần đây, mô hình kinh doanh trên toàn cầu tiếp tục thay đổi đáng kể với sự ra đời và phát triển mạnh mẽ của TMĐT. Mô hình kinh tế này đã có những đóng góp lớn cho sự tăng trưởng kinh tế trong bối cảnh thế giới đang bước vào cuộc cách mạng 4.0. Theo "Sách trắng Thương mai điện tử Việt Nam 2019", doanh số thương mại điện tử B2C trên toàn thế giới cũng đạt được những con số tăng trưởng ấn tượng, như doanh số của mô hình này năm 2019 đạt 2,027 tỷ đô la Mỹ và mức tăng trưởng lên 11 tỷ đô la Mỹ hơn 2,7\% so với năm 2018. Đến 2020, tỷ lệ này đạt 12\% trên doanh số 2,271 tỷ đô la Mỹ.(Ban biên tập Cục Thương mại điện tử và Kinh tế số, 2019) 
Internet Economy của Việt Nam trong giai đoạn 2015 - 2025

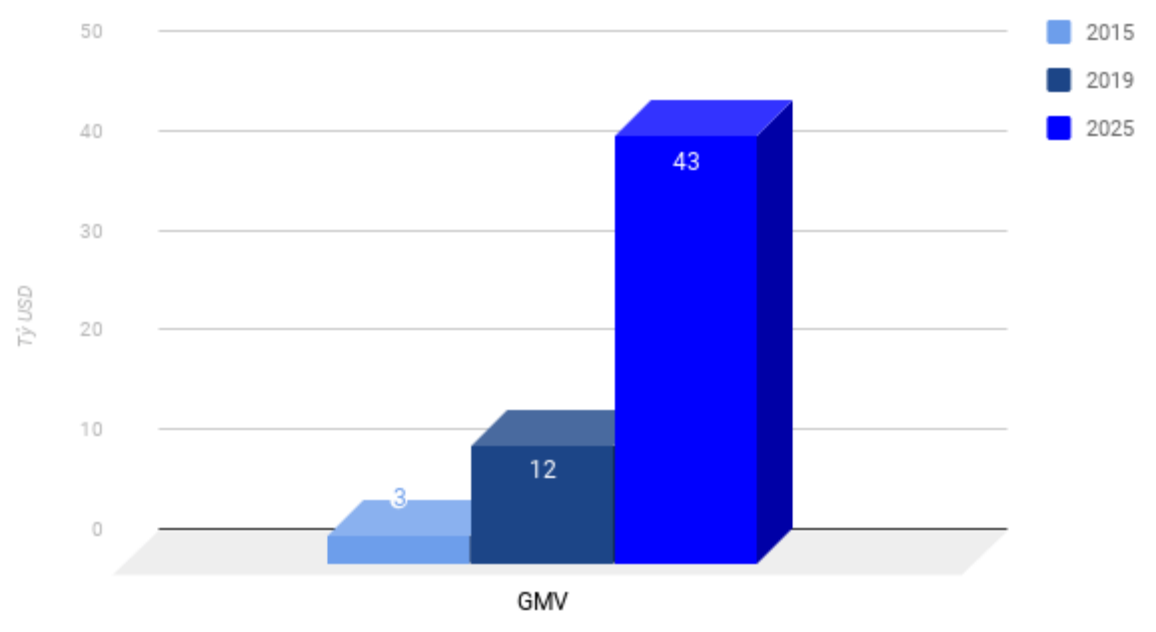

Quy mô của thị trường kinh tế kỹ thuật số ở Đông Nam Á cũng đã mở rộng ra một cách rộng rãi. Cụ thể, doanh thu của loại hình này chỉ đạt 5,5 tỷ USD trong khu vực vào năm 2015 , nhưng đã đạt 5,5 tỷ USD vào năm 2018. 23,2 tỷ đô la. Loại hình kinh doanh này dự kiến sẽ đạt con số ấn tượng 102 tỷ đô la vào năm 2025.(Đỗ Thị Nhâm, Đỗ Thị Huệ, 2020)

Internet users in Vietnam

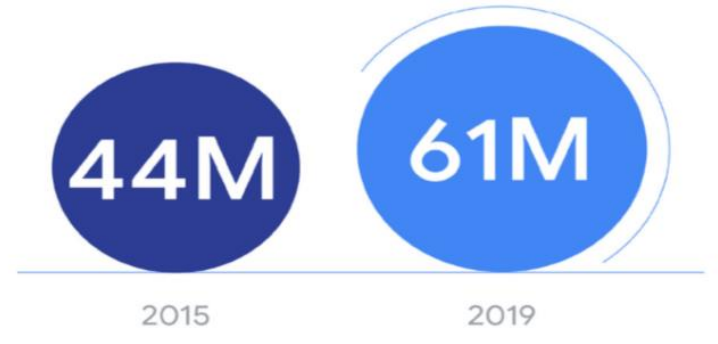

Lương người sủ dụng internet Việt Nam tăng mạnh trong 4 năm.(Pham, 2019)

=> Việt Nam hiện được coi là một trong những thị trường thương mại điện tử phát triển nhanh nhất Đông Nam Á với tốc độ tăng trưởng trung bình hàng năm hơn $25 \%$ và được dự báo sẽ đạt quy mô thị trường lên đến 13 tỷ đô la Mỹ vào năm 2020. E - Thương mại Việt Nam cũng đã trở thành một trong những thị trường có tiềm năng Trong những năm gần đây, mô hình kinh doanh trên toàn cầu tiếp tục thay đổi đáng kể với sự ra đời và phát triển mạnh mẽ của TMĐT. Mô hình kinh tế này đã có những đóng góp lớn cho sự tăng trưởng kinh tế trong bối cảnh thế giới đang bước vào cuộc cách mạng 4.0 lớn nhất trong khu vực ASEAN. Đây là một 
bước phát triển tất yếu, phù hợp với xu thế chung của thế giới và đồng thời cũng là bước đệm cho những phát triển sau này của nền TMĐT nước ta.

Bên cạnh những thành tựu đáng kể đã đạt được của TMĐT Việt Nam, ta thấy được một số khó khăn đã khiến TMĐT chưa phát triển tối đa trong những năm 2006 - 2019.(Ban biên tập Đại học Đông Á, 2021)

Đơn cử như dịch vụ logistics - giao hàng chặng cuối - hoàn tất đơn hàng còn nhiều hạn chế. Dù có đến trên $70 \%$ người mua hàng trực tuyến sử dụng hình thức thanh toán dịch vụ thu hộ người bán $(\mathrm{COD})$ nhưng tỷ lệ người mua hoàn trả sản phẩm đã đặt hàng trực tuyến còn cao. Ước tính, tỷ lệ trung bình tổng giá trị của các sản phẩm hoàn trả so với tổng giá trị đơn hàng lên tới $13 \%$, có doanh nghiệp phải chịu tỷ lệ này ở mức $26 \%$. Điều này gây khó khăn rất lớn cho các phần lớn các doanh nghiệp hiện nay.

Thêm vào đó, lòng tin của người tiêu dùng vào giao dịch mua bán trực tuyến còn thấp. Kết quả báo cáo cho thấy, tỷ lệ người mua hàng trực tuyến lựa chọn hình thức thanh toán tiền mặt khi nhận hàng $\mathrm{COD}$ còn rất cao - đến $88 \%$. Đây cũng là một vấn đề rất lớn đang tồn tại với TMĐT Việt Nam. Báo cáo cũng thống kê được, chỉ có $48 \%$ người được hỏi hài lòng với phương thức mua hàng trực tuyến, tức là vẫn còn một tỷ lệ lớn đối tượng khách hàng tiềm năng mà các nhà cung cấp dịch vụ TMĐT phải chinh phục.

Bảo mật thông tin, an toàn cho doanh nghiệp và khách hàng: Vấn đề bảo mật thông tin thực sự là vấn đề đáng lo ngại hiện nay. Nhiều khách hàng lo lắng bị lộ thông tin khi mua hàng online và trên thực tế điều này đã xảy ra. Nhiều người bị lộ thông tin và phải nhận những đơn hàng giả mạo. Để cải thiện tình trạng này, các sàn TMĐT cần nâng cao chế độ bảo mật và phải đảm bảo quyền lợi cho người tiêu dùng.

Hình thức thanh toán trực tuyến còn hạn chế: Hiện nay, các hình thức thanh toán trực tuyến còn gặp rất nhiều hạn chế. Dù các ví điện tử, các cổng thanh toán được mở ra khá đa dạng nhưng hiệu quả chưa thực sự tốt.Lý do là bởi ví điện tử và các ngân hàng tại Việt Nam đồng bộ vẫn đang gặp nhiều khó khăn.

Cơ sở hạ tầng chưa tối ưu: Cơ sở hạ tầng bao gồm cả công nghệ lẫn cơ sở giao thông vận chuyển chưa được tối ưu. Hệ thống máy chủ vẫn còn tình trạng tắc nghẽn. Hệ thống giao thông chưa được phát triển khiến thời gian giao hàng lâu và chi phí còn cao. Để phát triển TMĐT cần phải khắc phục những trở ngại này. 


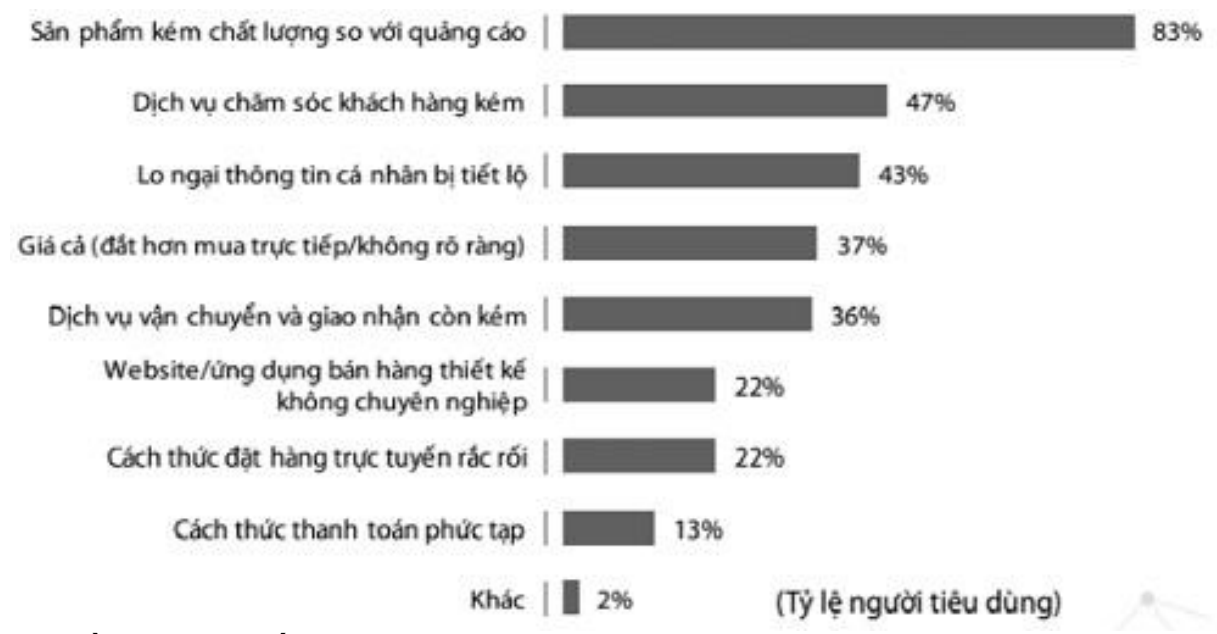

Nguồn: Sách trắng Thương mại điện tử Việt Nam 2019

Tóm lại, TMDT là xu thế của xã hội. Trong bối cảnh dịch bệnh COVID-19, TMĐT càng có cơ hội phát triển. Sử dụng hệ xử lý thông tin 3D (Vuong, Q.H., 2022), để thúc đẩy TMĐT ở VN cần có chiến lược bài bản đồng bộ các giải pháp, từ đầu tư cho khoa học công nghệ trong lĩnh vực TMĐT (Vuong, 2018), thông tin tuyên truyền, đến xây dựng hạ tầng cơ sở thông tin, chuyên gia và hợp tác giữa các bên liên quan (nhà nước, doanh nghiệp, người tiêu dùng, chuyên gia..).

\section{$\underline{\text { References }}$}

Ban biên tập Cục Thương mại điện tử và Kinh tế số. (2019). Thương mại điện tử B2C toàn cầu. In Sách trắng Thương mại điện tử Việt Nam (p. 20). Cục Thương mại điện tử và Kinh tế số.

Ban biên tập Cục Tin Học Hóa. (2014). Khái niệm đầy đủ của thuơng mại điện tử P1. Cổng Thông Tin Điện Tử Cục Tin Học Hóa. https://aita.gov.vn/ebiz/khai-niem-day-du-cuathuong-mai-dien-tu-p1

Ban biên tập Đại học Đông Á. (2021). Thưc trạng ngành TMĐT ở Việt Nam hiện nay. Cổng Thông Tin Điện Tử Đại Học Đông Á. https://tuyensinhdonga.edu.vn/thuong-mai-dien-tu-oviet-nam/

Ban biên tập Luật sư X. (2021). Thuơng mại điện tư là gì? Các mô hình thuơng mại điện tủ? Luật Sư X. https://luatsux.vn/thuong-mai-dien-tu-la-gi-cac-mo-hinh-thuong-mai-dien-tu/

Ban biên tập Quản lý doanh nghiệp. (2020). Các phuoong tiện thực hiện thuoong mại điện. Quản Lý Doanh Nghiệp. http://quanlydoanhnghiep.edu.vn/cac-phuong-tien-thuc-hien-thuongmai-dien-tu/

Đỗ Thị Nhâm, Đỗ Thị Huệ, N. T. L. (2020). Phát triển thương mại điện tử ở Việt Nam: Thưc trạng và kiến nghị. Tạp Chí Công Thương. http://tapchicongthuong.vn/bai-viet/phat-trienthuong-mai-dien-tu-o-viet-nam-thuc-trang-va-kien-nghi-72700.htm 
La, V. P. et al. (2020). Policy response, social media and science journalism for the sustainability of the public health system amid the COVID-19 outbreak: The vietnam lessons.

Sustainability (Switzerland), 12(7). https://doi.org/10.3390/su12072931

Nguyễn Ngọc Hưng. (2017). Thương mại điện tử Việt Nam 11 năm nhìn lại: Tổng quan và dụ báo. Seongon. https://seongon.com/blog/marketing-online/thuong-mai-dien-tu-vietnam.html

Pham, L. (2019). Góc nhìn toàn cảnh 2019: Kinh tế internet- TMĐT Việt Nam và nhũng dụ đoán trong năm 2020. Magenest. https://magenest.com/vi/goc-nhin-toan-canh-2019-kinh-teinternet-thuong-mai-dien-tu-viet-nam/

Trần Thị Kim Phượng. (2018). Phát triển thuoong mại điện tủ tại Việt Nam. Tạp Chí Công Thương. http://tapchicongthuong.vn/bai-viet/phat-trien-thuong-mai-dien-tu-tai-viet-nam53866.htm

Vuong, Q.H., et al. (2022). Covid-19 vaccines production and societal immunization under the serendipity-mindsponge-3D knowledge management theory and conceptual framework. Humanities \& Social Sciences Communications, 9, 22. Retrieved from: https://www.nature.com/articles/s41599-022-01034-6

Vuong, Q. H. (2018). The (ir)rational consideration of the cost of science in transition economies. Nature Human Behaviour, 2(1), 5. https://doi.org/10.1038/s41562-017-0281-4 